\title{
Comparison of three serological methods for diagnosing Mycoplasma pneumoniae infection
}

\author{
M Karppelin, K Hakkarainen, M Kleemola, A Miettinen
}

\begin{abstract}
Aims-To compare the novel Serofast latex agglutination test (International Mycoplasma, Toulon-Cedex, France) with the complement fixation test and enzyme immunoassay (EIA) for diagnosing acute Mycoplasma pneumoniae infection.

Methods-Paired sera from 60 patients with respiratory infection who had tested positive for $M$ pneumoniae by complement fixation test were analysed with Serofast and indirect EIA for specific IgG and IgM antibodies.

Results-Serofast was less sensitive than the two other tests. Only $30(50 \%)$ out of 60 paired sera which showed a diagnostic seroconversion or had high positive, unchanged antibody titres by complement fixation test or EIA, or both, tested positive with Serofast. Positive test results with Serofast were associated with the presence of a complement fixation test titre of $\geqslant 512$ and high positive IgM antibody titres measurable by EIA; virtually all patients with a complement fixation test titre of $<256$ or those responding primarily in the IgG class tested negative with Serofast. Based on analysis of sera taken at the acute phase of infection, $10(17 \%)$ of the 60 patients tested positive by complement fixation test, 10 (17\%) by EIA, and only four (7\%) by Serofast.
\end{abstract}

Conclusions-Serofast was less sensitive than complement fixation test and EIA and it cannot be recommended as a replacement for either test in routine diagnostic use. It might prove useful in laboratories where non-specific tests, such as the determination of cold agglutinins, are still used for the diagnosis of $M$ pneumoniae infection. Testing paired sera is, however, a prerequisite for obtaining acceptable sensitivity by Serofast as well as other serological methods currently available.

(F Clin Pathol 1993;46:1120-1123)

Mycoplasma pneumoniae is a common respiratory pathogen the symptoms of which range from mild respiratory infection to pneumonia. The infection is endemic but epidemics occur every few years. ${ }^{12}$ The infection spreads especially easily in institutions, where people are in close contact with each other. This fact explains, at least partially, why school children and their parents are those most at risk and children under three years of age and adults over 40 are less frequently affected. ${ }^{134}$

$M$ pneumoniae grows slowly and its culture is difficult and time consuming. The diagnosis of $M$ pneumoniae infection, therefore, is usually based on serology. Even today, the complement fixation test is the most widely used method for the diagnosis of $M$ pneumoniae infection, though its limitations in terms of specificity and sensitivity are well recognised. ${ }^{5-8}$ Thus there is a need for serological tests which could be used in the early diagnosis of $M$ pneumoniae infection. In fact, several test applications are currently being offered for this purpose - indirect enzyme immunoassay (EIA), $\mu$-capture enzyme immunoassay, and gelatin particle agglutination methods. ${ }^{89}$

We evaluated the novel Serofast latex agglutination test (International Mycoplasma, Toulon-Cedex, France) by comparing it with an indirect enzyme immunoassay (EIA) for immunoglobulin G (IgG) and IgM antibodies, and conventional complement fixation test in the serological diagnosis of $M$ pneumoniae infection. We studied the test performance of the three serological methods by analysing acute and convalescent phase sera from patients with probable $M$ pneumoniae infection.

\section{Methods}

The study population comprised 55 men and five women with a mean age of 21 years, who presented with an illness compatible with acute mycoplasmal respiratory disease and tested positive for $M$ pneumoniae by complement fixation test. Most of the patients were military conscripts. Both acute and convalescent phase sera were available, taken at a mean interval of 17 days (range five to 73).

Complement fixation test was performed as described before. ${ }^{10} \mathrm{~A}$ fourfold or more seroconversion in paired sera or a stable high positive titre of $\geqslant 128$ was considered indicative of acute $M$ pneumoniae infection.

$M$ pneumoniae strain 133A was grown in Hayflick's medium ${ }^{11}$ until a change in the indicator colour was apparent. The broth culture was centrifuged at $7700 \times g$ for 20 minutes at $+4^{\circ} \mathrm{C}$. The pelleted $M$ pneumoniae cells were suspended into phosphate buffered saline (PBS), pH $7 \cdot 2$, and centrifuged as above. This washing procedure was repeated three times and, finally, the cells were disrupted by sonication. The resulting antigen
Correspondence to: Dr A Miettinen

Accepted for publication 29 July 1993 
Distribution of positive Serofast test results in relation to results of complement fixation test and ELA in paired sera from 60 patients

\begin{tabular}{|c|c|c|c|c|}
\hline & \multicolumn{2}{|c|}{ Acute phase sera } & \multicolumn{2}{|c|}{ Convalescent phase sera } \\
\hline & $\begin{array}{l}\text { Positive }^{*} \\
(n=10)\end{array}$ & $\begin{array}{l}\text { Negative } \\
(n=50)\end{array}$ & $\begin{array}{l}\text { Positive } \\
(n=49)\end{array}$ & $\begin{array}{l}\text { Negative } \\
(n=11)\end{array}$ \\
\hline $\begin{array}{l}\text { No of positive Serofast tests in: } \\
\text { EIA positivet sera } \\
\text { EIA negative sera }\end{array}$ & $\begin{array}{l}\text { 4/8 } \\
0 / 2\end{array}$ & $\begin{array}{l}0 / 2 \\
0 / 48\end{array}$ & $\begin{array}{l}29 / 48 \\
0 / 1\end{array}$ & $\begin{array}{l}0 / 4 \\
0 / 7\end{array}$ \\
\hline
\end{tabular}

*Complement fixation test titres of $\geqslant 128$ were considered positive.

IgG or IgM antibody titres exceeding the mean of normal population by $\geqslant 2 \mathrm{SD}$ were considered positive in the EIA.

¥The nominator shows the number of positive Serofast tests in each group. The denominator shows the total number of sera in each group.

was divided into small aliquots and stored at $-20^{\circ} \mathrm{C}$ until used.

Microtitre plates (Maxisorp, Nunc, Denmark) were sensitised with $150 \mu$ l (per well) of the antigen diluted to a protein concentration of $1.4 \mu \mathrm{g} / \mathrm{ml}$ in carbonate-bicarbonate buffer, $\mathrm{pH} 9 \cdot 6$, incubated overnight at $+37^{\circ} \mathrm{C}$ and washed three times with PBS containing $0.5 \% \mathrm{v} / \mathrm{v}$ Tween 20 . The serum samples were diluted 1 in 100 in PBS containing $0.05 \% \mathrm{v} / \mathrm{v}$ Tween $20,5 \% \mathrm{v} / \mathrm{v}$ horse serum, and $\mathrm{NaCl}$ (final concentration, $0.5 \mathrm{M})$. They were then added in duplicate (100 $\mu \mathrm{l}$ per well) to separate plates for determination of IgG and IgM and incubated for 90 minutes at $+37^{\circ} \mathrm{C}$. After three washings rabbit anti-human IgG and IgM (Dako, dilutions 1 in 4000 and 1 in 2000, respectively) were added to the appropriate plates, $100 \mu \mathrm{l}$ per well, and incubated 45 minutes at $+37^{\circ} \mathrm{C}$. Finally, after three washings alkaline phosphatase conjugated anti-rabbit Ig (Orion Diagnostica, Espoo, Finland), diluted 1 in

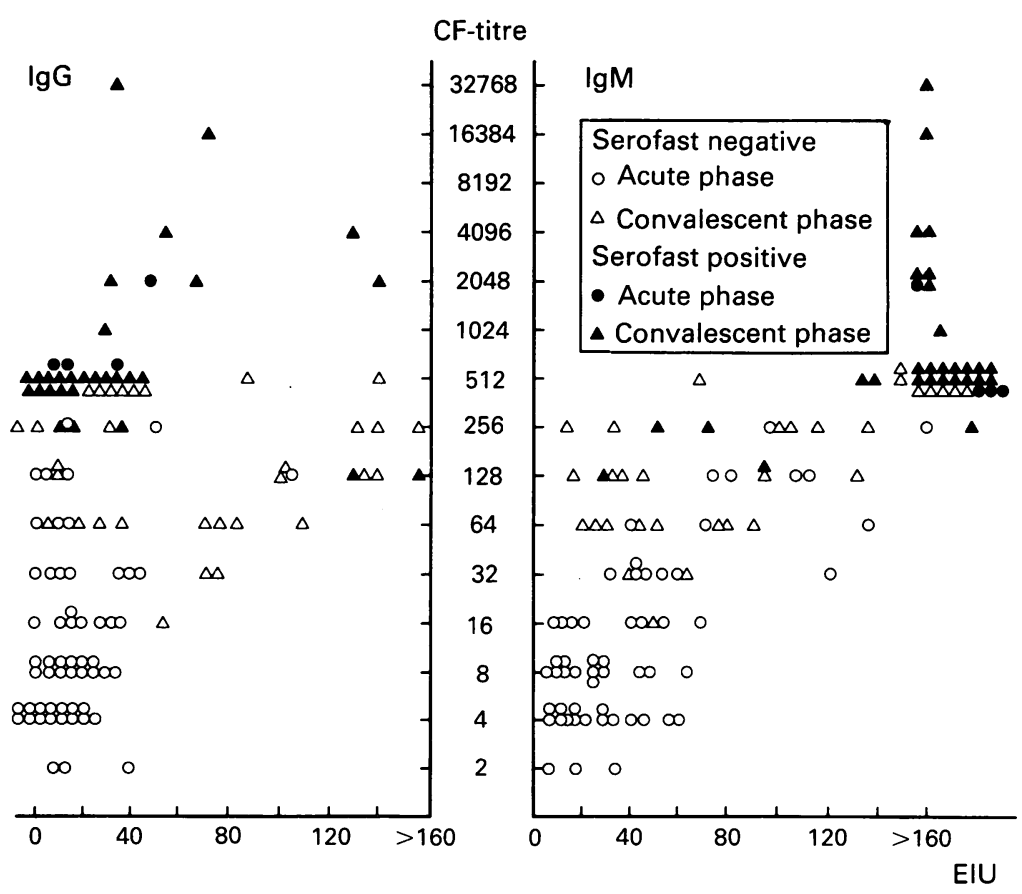

Correlation of serum antibodies to $M$ pneumoniae in paired sera from 60 patients with mycoplasmal respiratory infection as determined by enzyme immunoassay (ELA) for specific IgM and IgG antibodies, complement fixation (CF) test, and Serofast latex agglutination test.
$100,100 \mu \mathrm{l}$ per well, was incubated two hours at $+37^{\circ} \mathrm{C}$. After three additional washings $100 \mu \mathrm{l}$ of p-nitro-phenylphosphate$\mathrm{MgCl}_{2}$-buffer, $\mathrm{pH} 10 \cdot 0$, was incubated for 30 minutes at $+37^{\circ} \mathrm{C}$. Reaction was stopped with $100 \mu \mathrm{l} 0.3 \mathrm{M} \mathrm{NaOH}$ per well. Optical densities were recorded with a spectrophotometer (Titertek Multiscan, Eflab, Helsinki, Finland) at a wavelength of $405 \mathrm{~nm}$. Antibody titres were expressed in arbitrary EIA units (EIU), relative to negative and positive control sera, to give 0 EIU and 100 EIU, respectively.

The cutoff values for high positive antibody titres in the EIA had been predetermined in our routine laboratory as $\geqslant 100$ EIU for the IgM assay and $\geqslant 75$ EIU for the IgG assay, corresponding to the mean +2 SD of apparently healthy blood donors' sera. Based on monitoring the intra-and interassay variations in EIA, an increase of $\geqslant 20$ EIU in the IgM or IgG antibody titres between paired sera was also considered indicative of recent infection.

The Serofast test (Lot SB2351) was performed according to the manufacturer's instructions. In brief $25 \mu \mathrm{l}$ of the antigen suspension (latex particles coated with $M$ pneumoniae antigen) was mixed on the plate with $25 \mu \mathrm{l}$ of serum diluted 1 in 10,1 in 20 , and 1 in 40 and rotated gently. Reaction was read after four minutes. A positive reaction appeared as agglutination. A titre of $\geqslant 1 / 20$ was regarded as positive.

\section{Results}

A fourfold or higher seroconversion in complement fixation test occurred in $55(92 \%)$ of the 60 patients. In five the peak titre remained at $\leqslant 64$. Five $(8 \%)$ of the 60 patients already had a stable high $(\geqslant 128)$ complement fixation test titre in the acute phase serum.

When all the serum samples were considered, altogether $56(95 \%)$ of the 59 acute or convalescent phase sera with a high positive complement fixation test titre of $\geqslant 128$ tested positive in the EIA for IgM or IgG. Of the 61 sera with a complement fixation test titre of $<128,55(90 \%)$ tested negative in the EIA for IgM and IgG (table). Thus in discriminating between high positive and negative sera, the overall consistency between EIA and complement fixation test was $93 \%$. The correlation between EIA for IgM antibodies and complement fixation test titre was stronger $(r=0.824)$ than that between EIA for IgG antibodies and complement fixation test titre ( $r=0.341$ ) (figure).

Thirty (50\%) out of 60 cases, all of which were positive by complement fixation test or EIA, tested positive with Serofast. When only acute phase sera were considered, $10(17 \%)$ out of 60 cases tested positive for $M$ pneumoniae in EIA, $10(17 \%)$ in complement fixation test, and four $(7 \%)$ in Serofast. If a titre of 1/10 was considered positive with Serofast, two additional positive cases were detected.

Of the 33 sera testing positive by Serofast, 
$28(85 \%)$ were associated with a complement fixation test titre of $\geqslant 512$. Twenty nine $(88 \%)$ of them were associated with positive IgM in EIA, two (6\%) with positive IgG, and two $(6 \%)$ with both positive IgM and IgG (figure). The 55 seroconversions with complement fixation test were associated with positive IgG, IgM, or both by EIA in 12,24 , and 18 cases, respectively, with one pair remaining totally negative in EIA (data not shown). Of the former, one (8\%), $14(58 \%)$, and $12(67 \%)$, respectively, tested positive by Serofast.

\section{Discussion}

The early diagnosis of $M$ pneumoniae respiratory tract infections is difficult. Culture of the organism is time consuming and requires a specialised laboratory. Moreover, colonisation of the upper respiratory tract by $M$ pneumoniae in asymptomatic subjects has been reported, ${ }^{312}$ making the clinical value of a positive culture result uncertain. The sensitivity of Mycoplasma culture has been questioned, emphasising the importance of serological methods. ${ }^{1314}$ Novel methods available for the direct detection of $M$ pneumoniae include a species specific $\mathrm{CDNA}$ probe against $M$ pneumoniae $\mathrm{RNA}^{15}$ and a polymerase chain reaction test. ${ }^{16}$ The difficulty of obtaining adequate samples from the lower respiratory tract, however, will limit the routine use of these sophisticated methods. ${ }^{15}$

Complement fixation test is still the most widely used serological method in the diagnosis of $M$ pneumoniae infection. The need for paired sera and the recognition of false positive reactions in complement fixation test among patients with some extrapulmonary manifestations, such as meningitis and pancreatitis, ${ }^{5-7}$ has prompted the search for more advanced serological methods. The advantage of EIA based ${ }^{17}$ and indirect immunofluorescence methods ${ }^{9}$ is the possibility of detecting specific immunoglobulin classes separately: the demonstration of specific $\operatorname{IgM}$ antibodies allows earlier diagnosis of acute infections. The IgM antibodies reach diagnostic titres seven to 10 days from the onset of symptoms, while it usually takes longer for specific IgG to reach diagnostic titres. ${ }^{18-20}$

Considering the good agreement between test results using CF and EIA in all except two pairs of sera, it is reasonable to assume that most, if not all, of the 60 patients really had $M$ pneumoniae infection. The good correlation between results for IgM by EIA and complement fixation test was expected..$^{21}$ In contrast to an earlier report ${ }^{22}$ we did not, however, notice any significant correlation between EIA for IgG and complement fixation test.

The sensitivity of Serofast was much less than that of the other tests. Of 60 paired sera showing diagnostic seroconversion or stable high positive complement fixation test titres of $\geqslant 128$, only $30(50 \%)$ cases tested positive in Serofast. In only four (7\%) patients did the first serum sample taken at the acute phase of the infection test positive by Serofast. No significant increase in sensitivity was achieved by decreasing the cutoff value of Serofast. The specificity of Serofast was not assessed in this study.

The association between positive Serofast test results and the presence of high IgM antibody titres measurable by EIA was expected because IgM is far more efficient than IgG in agglutination reactions. The inability of Serofast to detect IgG class antibodies is probably a weakness inherent in many other agglutination tests. ${ }^{23}$

Among the relatively young patients in the present study the determination of IgG antibodies by EIA proved of limited diagnostic value. The IgG:IgM ratio is lower among this age group than older patients, ${ }^{21}$ and the superior test performance of the IgM assay to that of the IgG assay was anticipated. By using a $\mu$-capture EIA, a better sensitivity yet might have been obtained. ${ }^{9}$ The need to determine IgG antibodies in routine testing, on the other hand, is based on the fact that the IgG:IgM ratio increases in older age groups, ${ }^{21}{ }^{24}$ and in reinfected patients the IgM response may be totally absent. ${ }^{15} 19$

In conclusion, the Serofast latex agglutination test is no better for the rapid diagnosis of $M$ pneumoniae infection than currently available methods. It is important to examine both acute and convalescent phase sera while using any of the serological methods currently available.

1 Foy HM, Kenny GE, Cooney MK, Allan ID. Longterm epidemiology of infections with Mycoplasma pneumoniae. $\mathcal{F}$ Infect Dis 1979;139:681-7.

2 Lind K, Bentzon MW. Epidemics of Mycoplasma pneumoniae infection in Denmark from 1958 to 1974 . Int $\mathcal{f}$ Epidemiol 1976;5:267-77.

3 Foy HM, Grayston JT, Kenny GE, Alexander ER, McMahan R. Epidemiology of Mycoplasma pneumoniae infection in families. $\mathscr{F} A M A$ 1966;197:859-66.

4 Lind K, Bentzon MW. Ten and a half years seroepidemiology of Mycoplasma pneumoniae infection in Denmark. Epidemiol Infect 1991;107:189-99.

5 Kleemola $M$, Käyhty $H$. Increase in titers of antibodies to Mycoplasma pneumoniae in patients with purulent meningitis. F Infect Dis 1982;146:284-8.

6 Leinikki P, Pantzar P, Tykkä H. Antibody response in patients with acute pancreatitis to Mycoplasma pneumoniae. Scand $\mathcal{f}$ Gastroenterol 1973;8:631-5.

7 Pönkä A, Pönkä T, Sarna S, Penttinen K. Questionable specificity of lipid antigen in the Mycoplasma pneumoniae CF test in patients with extrapulmonary manifestations. $\mathcal{F}$ Infect 1981;3:332-8.

8 Barker CE, Sillis M, Wreghitt TG. Evaluation of Serodia Myco II particle agglutination test for detecting Mycoplasma pneumonia antibody: comparison with $\mu$ capture ELISA and indirect immunofluorescence. $\mathcal{F}$ Clin Pathol 1990;43:163-5.

9 Wreghitt TG, Sillis M. A $\mu$-capture ELISA for detecting Mycoplasma pneumoniae IgM: comparison with indirect immunofluorescence and indirect ELISA. direct immunofluorescence

10 Hawkes RA. General principles underlying laboratory diagnosis of viral infections. In: Lennette EH, Schmidt NJ, eds. Diagnostic procedures for viral, rickettsial and chlamydial infections. 5th edn. Washington, DC: American Public Health Association, 1979:35-42.

11 Grayston JT, Foy HM, Kenny GE. The epidemiology of Mycoplasma infections of the human respiratory tract. In: Hayflick L, ed. The mycoplasmatales and the L-phase of bacteria. Amsterdam: North-Holland, 1969:651-82.

12 Foy H, Kenny G, McMahan R, Kaiser G, Grayston J. Mycoplasma pneumoniae in the community. $A m \dot{f}$ Epidemiol 1970;93:55-67.

13 Kok T-W, Varkanis G, Marmion BP. Laboratory diagnosis of Mycoplasma pneumoniae infection 1. Direct detection of antigen in respiratory exudates by enzyme immunoassay. Epidemiol Infect 1988;101:669-84.

14 Kenny GE, Kaiser GG, Cooney MK, Foy HM. Diagnosis of Mycoplasma pneumoniae pneumonia: sensitivities 
and specificities of serology with lipid antigen and isolation of the organism on soy peptone medium for identification of infections. F Clin Microbiol 1990;28. 2087-93.

15 Kleemola SRM, Karjalainen JE, Räty RKH. Rapid diagnosis of Mycoplasma pneumoniae infection: clinica evaluation of commercial probe kit. $\mathcal{F}$ Infect Dis 1990 ; 162:70-5.

16 Skakni L, Sardet A, Just J, et al. Detection of Mycoplasma pneumoniae in clinical samples from pediatric patients by polymerase chain reaction. $\mathcal{f}$ Clin Microbiol 1992;30: $2638-43$.

17 Busolo F, Tonin E, Conventi L. Enzyme-linked immunosorbent assay for detection of Mycoplasma immunosorbent assay for detection of Mycoplasma

18 Jacobs E, Bennewitz A, Bredt W. Reaction pattern of human anti-Mycoplasma pneumoniae antibodies in human anti-Mycoplasma pneumoniae antibodies in 517-22.

19 Moule JH, Caul EO, Wreghitt TG. The specific IgM response to Mycoplasma pneumoniae infection: inter- pretation and application to early diagnosis. Epidemiol Infect 1987;99:685-92.

20 Vikerfors T, Brodin G, Grandien M, Hirschberg L, Krook A, Petterson C-A. Detection of specific IgM antibodies for the diagnosis of Mycoplasma pneumoniae infections: a clinical evaluation. Scand $\mathcal{F}$ Infect Dis 1988;20:601-10.

21 Dussaix E, Slim A, Tournier P. Comparison of ELISA and CF-test for detection of Mycoplasma pneumoniae antibodies. $f$ Clin Pathol 1983;36:228-32.

22 Hirschberg L, Holme T, Krook A, Vikerfors T. IgG response to Mycoplasma pneumoniae in patients with community acquired pneumonia determined by ELISA. APMIS 1988;96:605-10.

23 Nichols WS, Nakamura RM. Agglutination and agglutination inhibition assays. In: Rose NR, Friedman H, Fahey $\mathrm{JL}$, eds. Manual of clinical laboratory immunology. 3rd $\mathrm{J}$, eds. Manual of clinical laboratory immunology. 3rd edn. Washington, DC

24 Mizutani H, Mizutani H. Immunologic responses in patients with Mycoplasma pneumoniae infections. $A m$ Rev Respir Dis 1983;127:175-9. 